\title{
Trabalho Penitenciário-Saúde-Formação \\ a Comunidade Ampliada de Pesquisa como Dispositivo
}

Prison Labor-Health-Education

the Extended Research Community as a device

Trabajo Penitenciario-Salud-Formación

La Comunidad Ampliada de Investigación como Dispositivo

\section{Fernanda Spanier Amador}

Universidade Federal do Rio Grande do Sul, Porto Alegre, RS, Brasil.

Dafni de Melo

Grupo Hospitalar Conceição, Porto Alegre, RS, Brasil.

\section{Lucas Bueno}

Universidade Federal do Rio Grande do Sul, Porto Alegre, RS, Brasil.

\section{Sandra Correia}

Universidade Federal do Rio Grande do Sul, , Porto Alegre, RS, Brasil.

\section{Simone Reginato}

Secretaria da Segurança Pública, Porto Alegre, RS, Brasil.

\section{Christyanne Alves}

Universidade de São Paulo, São Paulo, SP, Brasil.

\section{Resumo}

Este artigo relata aspectos da experiência de extensão e pesquisa que estamos desenvolvendo em parceria UFRGS e SUSEPE pelos quais visamos à tríade Trabalho Penitenciário-Saúde-Formação. Tendo como referenciais a Ergologia e a Clínica da Atividade, apresentamos a concepção do projeto de extensão que consistiu, ao mesmo tempo, no desenvolvimento da primeira etapa da pesquisa, seus objetivos e estratégias, além de comentários relativos ao processo que tem, nas Comunidades Ampliadas de Pesquisa, um dispositivo.

Palavras-Chave: Trabalho penitenciário; Saúde; Formação; Comunidade ampliada de pesquisa; Dispositivo.

\footnotetext{
Abstract

This paper describes features of the extension and research program experience we have been developing in partnership with UFRGS and SUSEPE in which we address the triad Prison Labor- Health-Training. Considering Ergology and Clinical Activity as references, we present the
} 
conception of the extension project which consisted, at the same time, of developing the first stage of the research, its objectives and strategy, as well as producing comments about the process which can find in the Extended Research Communities a device.

Key-Words: Prison Labor, Health, Education, Extended Research Communities; Device

\section{Resumen}

Este artículo describe aspectos de la experiencia de extensión e investigación que estamos desarrollando en colaboración con la UFRGS y SUSEPE por los cuales nos direccionamos hacía la tríada Trabajo Penitenciario-Salud-Formación. Al considerar la Ergología y la Clínica de la Actividad como referenciales, presentamos la concepción del proyecto de extensión que consistió, al mismo tiempo, en el desarrollo de la primera etapa de la investigación, sus objetivos y estrategia, además de comentarios relativos al proceso que posee, en las Comunidades Amplias de Investigación, un dispositivo.

Palabras-clave: Trabajo Penitenciario; Salud; Formación; Comunidad Ampliada de Investigación; Dispositivo.

\section{Introdução}

Este artigo relata aspectos relativos à experiência de dois projetos articulados, um de extensão e outro de pesquisa, desenvolvidos junto a trabalhadores do Sistema Prisional. A ação de extensão intitula-se Trabalho Penitenciário-Saúde-Formação - constituição de Comunidades Ampliadas de Pesquisa (CAPs) e teve por objetivo, criar as condições de possibilidade para o desenvolvimento de projeto de pesquisa-intervenção junto a trabalhadores penitenciários de uma Casa Prisional de Porto Alegre. O referido projeto se intitula Clínicas do Trabalho e Paradigma Estético: atividade, subjetivação e linguagem por experimentaRev. Polis e Psique, 2013; 3(2):185-206 ções imagético-digitais com trabalhadores do Sistema Penitenciário ${ }^{1}$ e encontra-se em curso. Considerando que a primeira etapa da pesquisa-intervenção prevê aproximação com o campo para produzir suas condições de viabilidade, as ações da extensão foram, concomitantemente, ações também previstas no projeto de pesquisa.

Tomando como lastro o campo da Saúde do Trabalhador, termo consolidado enquanto conceito nos textos legais pela Lei Orgânica da Saúde (Lei 8.080 de 19 de setembro de 1990), operamos no escopo de conhecimentos que nasceu para contrapor os modelos hegemônicos da Medicina do Trabalho, Engenharia de Segurança e Saúde Ocupacional. Nessa perspectiva, os im- 
pactos dos ambientes e as formas de organização e de gestão do trabalho na vida dos trabalhadores são analisados a partir da determinação histórica e social dos processos de saúde e doença, dos quais o trabalhador é sujeito ativo. Assim, as ações que abordamos aqui situam a atenção à saúde dos servidores penitenciários e a própria formação para o trabalho, nos espaços cotidianos laborais ao invés de localizá-la nos gabinetes dos profissionais especializados, esses, muitas vezes, distantes do que se passa no trabalho em situação.

Os projetos desenvolvidos respondem de alguma maneira, à convocação expressa no texto da Política Nacional de Segurança e Saúde do Trabalhador (2004), qual seja, o de estimular a produção de estudos e pesquisas na área articulando instituições de ensino e universidades, o que estamos efetivando mediante o envolvimento dos trabalhadores penitenciários nesse processo e valorizando seu conhecimento empírico relativo aos aspectos organizacionais, institucionais e ambientais do trabalho no sistema prisional.

Convergindo com o enfoque da Política Nacional de Educação Permanente em Saúde (PNEPS), que aqui é levada a termo na inspiração de apostarmos em uma espécie de Educação Permanente no Serviço Penitenciário, salientamos também que as estratégias adotadas favorecem: “o propósito Rev. Polis e Psique, 2013; 3(2):185-206 de incorporação do ensino e do aprendizado à vida cotidiana das organizações e às práticas sociais e laborais, no contexto efetivo onde ocorrem; a modificação substancial das estratégias educativas, que passam a valorizar a prática como fonte de conhecimento e de problemas; a problematização do próprio fazer pelos trabalhadores; a colocação das pessoas como atores reflexivos da prática e construtores do conhecimento e de alternativas de ação, ao invés de seus receptores e a ampliação dos espaços educativos fora da aula e dentro das organizações (...)" (Brasil, 2009, p.44).

Além disso, há pertinentes aproximações de nossas ações com os propósitos do Programa de Valorização e Atenção a Saúde Física e Mental do Servidor e Servidora do Estado do Rio Grande do Sul (PROSER), recente Política Pública de Estado aprovada pelo Decreto 48.898 de 06/03/2012, que vem sendo construída sob a coordenação da Secretaria da Administração e dos Recursos Humanos (SARH), juntamente com as Secretarias de Segurança Pública (SSP), Secretaria da Educação (SEDUC), Secretaria da Saúde (SES), Casa Civil e Instituto de Previdência do Estado (IPE). E ainda, com as discussões da Primeira Conferência Nacional de Segurança Pública, ocorrida em Brasília em agosto de 2009, em seus propósitos de uma segurança com desenvolvimento e liberdade com defe- 
sa de investimentos em educação e em valorização dos profissionais.

Tais movimentos que resultam em Políticas Públicas e em Políticas de Governo, aqui referidas, reforçam a necessidade de ações conjuntas entre as Universidades e os órgãos de Segurança Pública de modo a contribuir para o atingimento de tais diretrizes e propósitos. Nesse lastro, a ideia da constituição de CAPs comparece como um recurso convergente, sobretudo, com as prerrogativas das Políticas em Saúde do Trabalhador porque podem fomentar ações que deslocam a posição de saber dos especialistas em saúde para criar espaços de co-gestão da saúde com os próprios trabalhadores interessados, os quais passam a ser agentes de transformação das suas próprias realidades, discutindo e informando o que para eles é prioridade.

As CAPs fazem parte de uma proposta de Yves Schwartz (2000) inspirada nas experiências do Modelo Operário Italiano que visa à constituição de coletivos formados por pesquisadores-universitários e pesquisadores-trabalhadores para colocação em análise da atividade laboral. Por essa última, a atividade, entendendo-se a dimensão que no trabalho escapa à tarefa a ser cumprida consistindo, em lugar disso, em uma renormatização incessante do trabalho (Schwartz, 2000), lugar do que se faz, do que não se faz, do que se pensa em fazer, lugar de sonho e de criação (Clot, 2010a).

Tomando como referenciais a Ergologia (2000) e a Clínica da Atividade (2010a), ambas abordagens do chamado campo das Clínicas do Trabalho, o projeto de extensão e a pesquisa que aqui abordamos, visam fomentar a constituição de coletivos entre os servidores do sistema prisional, os quais, juntamente com extensionistas e pesquisadores universitários, põem em análise seus modos de trabalhar e de estabelecer as conexões trabalho-saúde-formação.

Assim, em um primeiro momento, essa dimensão foi discutida entre servidores que desenvolvem seu trabalho na Escola de Serviços Penitenciários (ESP), no Serviço de Atenção ao Servidor da SUSEPE (SASS) e no Instituto Penal Feminino (IPF-POA), incluindo, mais adiante, o Departamento de Recursos Humanos (DRH-SUSEPE) e o Departamento de Planejamento (DEPLAN-SUSEPE) e, a partir desse movimento, atingiu-se a possibilidade de sustentação de uma ação em Clínicas do Trabalho em uma Casa Prisional específica. Tal ação configura o projeto de pesquisa que mencionamos pelo qual são colocados em análise os fazeres laborais penitenciários cotidianos dando a ver como os trabalhadores e trabalhadoras conseguem fazer de suas experiências meio para novas experiências e, ainda, quando são impedidos disso. Deste modo, a propos- 
ta metodológica da pesquisa vem se configurando como experimentação de uma certa modalidade de atenção à saúde com caráter coletivo, bem como de formação com caráter igualmente coletivo e permanente.

O objetivo geral da extensão e da primeira etapa da pesquisa consistiu, então, em propor uma aproximação do campo empírico das prisões no Rio Grande do Sul, em especial na cidade de Porto Alegre/RS, visando promover ações de atenção à saúde do trabalhador penitenciário por meio da formação de CAPs. Desta experiência dialógica resulta o presente artigo, fruto da autoria de trabalhadores universitários e de trabalhadores penitenciários, buscando com isso, evidenciar os movimentos empreendidos pela ação de extensão e, posteriormente também, pelo projeto de pesquisa, os quais objetivam romper com as rígidas fronteiras, muitas vezes estabelecidas, entre mundo acadêmico e campo empírico da pesquisa.

\section{Ergologia e clínica da atividade}

\section{abordagens para pesquisar e intervir junto aos trabalhadores penitenciários}

Quando o que está em questão é o trabalho penitenciário, vários desafios ganham a cena. Inicialmente, destaca-se a carência de estudos e pesquisas na área quando comparado com outras categorias profissionais, apesar das constantes mani- festações dos efeitos nocivos do trabalho para a saúde dos trabalhadores penitenciários. Destaca-se, ainda, o fato de que os estudos, quando realizados, concentram-se, sobremaneira, em aspectos relativos às precárias condições de trabalho. Aliados a tais precariedades, aparecem os quadros de sofrimento e de adoecimento, os quais, geralmente em formato de percentuais, reiteram uma situação problemática que convoca à investigação.

Em levantamento bibliográfico encontramos pesquisas de diversas localidades do país e com grande variedade de métodos, como por exemplo: pesquisa etnográfica desenvolvida com agentes penitenciárias femininas paulistas a qual consistiu em, a partir da coleta de narrativas sobre a trajetória profissional, compreender as representações que tais profissionais criam sobre as relações no interior dos presídios (Taets, 2011), pesquisa de caráter epidemiológico para identificar possíveis associações entre condições de trabalho e saúde de agentes penitenciários de Salvador/BA, a qual se valeu de questionários autoaplicáveis com perguntas que visavam à coleta de informações sócio-demográficas, de aspectos ocupacionais, de hábitos de vida e de morbidade geral e ocupacional (Fernandes et al, 2002) e pesquisa qualitativa expondo a falibilidade do funcionamento prisional gerando o fenômeno definido como prisionalização 
(Lopes, 2002). Já Carvalhaes \& Lima (2010), Fernandes, Neto, Sena, Leal, Carneiro \& Costa (2002) e Harkot-de-La-Taille (2008) mapeiam as patologias derivadas do trabalho, as violências sofridas e praticadas e seus desdobramentos em implicação com o uso de drogas, bem como os impactos do trabalho penitenciário no espaço fora das Casas Penitenciárias uma vez que os trabalhadores sinalizam viver uma sensação de vulnerabilidade relacionada a ameaças proferidas por aqueles que se encontram cumprindo pena.

Observa-se que pesquisas qualitativas são realizadas evidenciando percepções e sentimentos dos trabalhadores penitenciários, contudo, raros são os estudos que analisam a processualidade de sua atividade a qual implica incursionar pelo agenciamento do pensamento dos trabalhadores penitenciários quando da gestão da distância entre o Trabalho Prescrito e o Trabalho Real, tal como é o objetivo dos projetos que aqui abordamos e de outros estudos que já realizamos junto a mulheres trabalhadoras do sistema prisional (Amador, 2009).

Tomar o pensamento em termos de seu agenciamento implica uma heterogeneidade de instâncias envolvidas nesse processo, deslocando-o de uma exclusividade central do cérebro daquele pensa. Um pensamento agencia-se pelo corpo em conexão com outros corpos remetendo para a criação (Souza, 2012) e essa é, justamente, a dimen- são em análise pelos referenciais Clínicos do Trabalho adotados em nossos projetos, uma vez que para ambos, interessa a análise da atividade de trabalho.

Trabalhar é gerir, diz Yves Schwartz (2004). Assim, trabalhar é fazer coisas junto, é fazer a gestão das imprevisibilidades sempre presentes em situação de trabalho já que, como ensinam os ergonomistas, entre o Trabalho Prescrito e o Trabalho Real há sempre uma distância, uma defasagem pela qual as experiências da gestão e da criação coletivas, ganham terreno.

Para além de metas estabelecidas pelas instâncias de gestão administrativa presentes nas mais diversas organizações de trabalho, há uma instância de gestão operada na atividade de trabalho pelos trabalhadores durante o exercício de seu ofício, a qual diz respeito a um plano de singularizações que gera um gênero profissional (Clot, 2010 a), esse o lastro de uma coletividade de trabalhadores. Assim, pensar o trabalho desde a perspectiva da atividade implica reconhecer que nele sempre se lida com uma dimensão imediata da situação, que engaja e transforma, ao mesmo tempo, aquele que a executa (Teiger, 1998). A autora, deste modo, destaca um caráter de imprevisibilidade da atividade que requer, a cada instante, a inteligência criadora de trabalhadores e trabalhadoras. Além disto, salienta a existência de uma irredutibilidade que evidencia 
o enigma da atividade situado em uma fronteira muito pouco nítida entre um pensamento capaz de representar e de solucionar problemas e aquele afeito a seguir os rastros indiscerníveis do (i)representável para abrir sendas problemáticas relativas ao trabalho, sendas essas capazes de fazê-lo nascer de modos ainda não existentes (Amador, 2009).

Diz Schwartz (2000) que ao executar o trabalho se vive dramáticas dos usos de si, ou seja, as pessoas fazem escolhas conscientes e inconscientes - e em função de determinados critérios, o que expressa que há valores orientando essas escolhas. $\mathrm{O}$ autor afirma, também, que há “debates de normas" - debates consigo mesmo e debates de ordem social, do "bem viver juntos" os quais, embora geralmente não sejam vistos, estão no interior mesmo da mais ínfima atividade do trabalho.

Do ponto de vista da promoção da saúde e da formação viabilizadas por tal abordagem trata-se de pensar que a criação de espaços de análise da atividade de trabalho com os trabalhadores propicia a expansão de seu poder de agir (Clot, 2010 a), isto é, de sua potência de trabalhar diferentemente, de traçar novos objetivos a partir dos resultados inesperados atingidos no trabalho e, consequentemente, de assim produzir saúde interferindo diretamente nos modos de sociabilidade produzidos pelo trabalho.
A partir daí, entende-se que o sofrimento laboral se produz pelos empecilhos à singularização dos trabalhadores, singularização que, em última instância, alavanca uma formação operada pela própria experiência do trabalho já que se expressa como abertura a novos modos de trabalhar, resultantes de questões formuladas pelos próprios trabalhadores acerca de suas práticas.

Deste modo, a ideia de clínica e de atenção à saúde, presente na abordagem da Clínica da Atividade, consiste em apostar em uma espécie de clínica ampliada, ou seja, deslocada dos moldes tradicionais de atendimento muitos deles individualizados e até mesmo individualizantes, na medida em que não consideram os elementos sociais envolvidos na produção do sofrimento e do adoecimento no trabalho. Além disto, sinaliza para a importância da promoção da saúde visando intervir pelo fortalecimento dos coletivos de trabalho nas situações analíticas da gestão de sua atividade, o que pode, em última instância, contribuir para a permanente crítica dos modos de organização do trabalho e das instituições que nela se materializam reinventando, permanentemente, os saberes no trabalho.

Neste sentido, vale destacar a forte influência do pensamento de Canguilhem (2011) para quem os trabalhadores são sujeitos de um meio de organização que têm necessidade de criar assumindo responsa- 
bilidade por seus atos, bem como de trazer coisas para a existência estabelecendo relações entre elas. Canguilhem propõe, em última análise, que estabeleçamos uma inversão na perspectiva de pensar as normas do trabalho, frequentemente tomadas pela via da racionalização, reconhecendo-lhes sua dimensão filosófica, o que se torna chave para entender sua concepção de saúde no trabalho. Para ele, não existe uma racionalização mas várias, não existe uma norma mas normas e os trabalhadores precisam ser sujeitos de suas normas porque as normas fazem, para homens e mulheres, o sentido de suas vidas. Assim, saúde é mais do que adaptar-se a uma norma, do que "ser normal", é sentir-se sujeito vivo de uma normatividade.

\section{Considerações a respeito da CAP como dispositivo}

Metodologicamente nossas ações vêm se configurando, pela referência que tomamos da Ergologia e da Clínica da Atividade enquanto estratégias para fazer emergir a capacidade dos pesquisadores-trabalhadores penitenciários de problematizarem o próprio trabalho no encontro com os pesquisadores-trabalhadores universitários, fazendo ver, falar e pensar, coletivamente, seus movimentos de enfrentamento do real do trabalho. Por isso, nossa estratégia não visa Rev. Polis e Psique, 2013;3(2):185-206 pesquisar os dados de uma situação, isto é, o conjunto das percepções dos trabalhadores ou o conjunto de dificuldades relativo à precariedade das condições de trabalho. Interessa-nos o que eles fazem com isso, como isso gera, na experiência, estratégias de enfrentamento, tendo um especial interesse, por seus fluxos de criação nesse processo.

Pelas Comunidades Ampliadas de Pesquisa, Schwartz (2000) chega ao conceito de Dispositivo Dinâmico a Três Polos, o qual implica em que pesquisadores universitários juntamente com os trabalhadores - pelo encontro de seus diferentes saberes (conceituais e oriundos da experiência de trabalho) -, vejam-se convocados em dimensão ético-epistemológica, isto é, a não se deixarem dominar uns pelos saberes dos outros e sim, de se permitirem encontrar na partilha de um plano problemático, quer dizer, de um plano de indagações que possibilite colocar em questão as formas cognitivas já constituídas por ambos, na direção da produção de novos saberes, a partir de seus fazeres profissionais. A CAP materializa, então, uma espécie de expansão das zonas de desvio no confronto dialógico com outros trabalhadores, pelas quais os trabalhadores em situação de trabalho buscam tornar o trabalho vivível mais do que executável. Referimo-nos aqui a vivível como sendo a dimensão vinculada à saúde, uma dimensão onde se viabiliza viver o trabalho e não apenas executá-lo, para 
deste modo, retirá-lo das amarras da repetição do mesmo. Pela CAP apostamos em um espaço para trabalhar coletivamente aquilo que é da ordem do coletivo de trabalho, isto é, do gênero profissional uma vez que para Clot (2010a) o Trabalho Coletivo é realizado pelas análises realizadas pelos trabalhadores acerca e a partir, do estoque de suas criações na atividade.

Por que entendemos a CAP como dispositivo? Porque inspirados no pensamento deleuziano (Deleuze, 1990), a CAP embaralha linhas de saber, poder e subjetividade, possibilitando aos trabalhadores, acadêmicos e penitenciários, a ampliação dos horizontes de tais linhas, de modo a ativar sua afeição pela apreensão do novo. Ou, dito de outro modo, para estarem atentos "ao desconhecido que toca à porta" (Deleuze, 2003), reinventando, assim, permanentemente, os modos de trabalhar.

Clot (2010b) observa que os primeiros psicólogos do trabalho já atentavam para o fato de que a atividade humana não ocorre segundo a sua prescrição. "O homem não se manifesta somente naquilo que ele faz, mas frequentemente e, sobretudo, naquilo que ele não faz" (Pacaud, citada em Clot, 2010b; p.209). A atividade humana está naturalmente envolta em obstáculos que o trabalhador precisa enfrentar no desempenho da tarefa, de forma que a atividade manifesta é apenas uma das muitas possíveis.
Tal enfrentamento é o que garante a possibilidade de seguir vivendo e produzindo saúde pelo trabalho por meio de um processo no qual o aprender e o fazer consistem na abertura de indagações acerca dos modos instituídos de trabalhar. É assim que podemos visualizar uma instância de formação para o trabalho operada quando do exercício do próprio trabalho, a qual caberia amplificar e potencializar em discussões coletivas para conferir-lhes tons ético-político-estéticos, isto é, para afirmar as potências de diferir, a mobilização de forças coletivas e a criação de novos modos de existência.

Como estamos compondo tal dispositivo em nossa experiência? Inicialmente procuramos, enquanto trabalhadores acadêmicos, a Escola do Serviço Penitenciário $(\mathrm{ESP})^{2}$ em janeiro de 2011 para apresentação da proposta, a qual a acolheu e vem sustentando as ações desde então. Em seu espaço, vêm ocorrendo reuniões mensais daquilo que estamos chamando de CAP-Transversal e, a partir dessa chegou-se a constituição de uma CAP no Instituto Penal Feminino (IPF-POA) que abriga mulheres cumprindo pena em regime semi-aberto. Nesta CAP localizam-se três coletivos para análise da atividade de trabalho, já enquanto segunda etapa da pesquisa: de técnicas, de agentes administrativos e de agentes de segurança. 
Em tais coletivos colocamos em discussão aquilo que os trabalhadores fazem, deixam de fazer, sonham em fazer, consideram enigmático fazer visando à emergência da diferença pelos relatos de como agem em seu trabalho, favorecendo a expansão do poder de agir.

Trata-se de fomentar análises que se situam no "devir do trabalho" em lugar do “dever ser do trabalho". A questão a discutir é o que e como os trabalhadores fazem, apesar dos impedimentos, muitas vezes a eles impostos nesse percurso fomentando visibilidades para as forças que os fazem recriar permanentemente seu trabalho e, por vezes, que os impedem, investindo nos trabalhadores como protagonistas de uma micropolítica nos cotidianos laborais, isto é, de procedimentos capazes de instaurar crítica e transformação de dimensões institucionais na esfera da gestão do trabalho cotidiano.

A partir daí, a ideia é amplificar as instâncias de diálogo para além dos espaços locais de trabalho, o que já vem ocorrendo nos encontros da CAP-Transversal, gerando movimentos em âmbito das políticas macroorganizacionais. Ressalta-se a importância desses espaços onde os trabalhadores verbalizam suas práticas, reforçando-se coletivamente e oportunizando uma outra possibilidade de elaboração dos conflitos.

Rev. Polis e Psique, 2013;3(2):185-206

\section{Objetivos, estratégias e movimentos}

Os objetivos específicos do projeto de extensão e da primeira etapa da pesquisa foram: explorar possibilidades de atenção à saúde dos trabalhadores do Sistema Penitenciário em indissociabilidade dos processos de formação para e no trabalho, oportunizar a formação mútua de trabalhadores do Sistema Penitenciário e de extensionistas universitários, na temática Trabalho Penitenciário-Saúde-Formação, criar condições de possibilidade para a realização de pesquisa-intervenção em Clínicas do Trabalho junto a os servidores da SUSEPE, criar instância articuladora na própria SUSEPE para difusão de ações em Clínicas do Trabalho e sustentação de seus efeitos geradores de transformação no que tange à organização e às condições de trabalho, contribuir para a inserção de profissionais do sistema penitenciário na rede de discussões e deliberações no que tange à Saúde do Trabalhador e favorecer a intersetorialidade, produzindo elementos que potencializam, especialmente, Políticas de Saúde do Trabalhador e Políticas de Justiça e Segurança.

\section{Para atingi-los, foram abertas linhas de ação: Linha I - acionando a CAP}

O primeiro movimento foi empreendido pelo grupo de pesquisadores univer- 
sitários o qual ofereceu a proposta de ação aos Servidores do Sistema Penitenciário mediante visita à Direção da ESP para apresentação do projeto. Tendo-se discutido as linhas gerais do trabalho procedeu-se, a seguir, ao estabelecimento de convênio UFRGS/SUSEPE para realização de projetos de extensão e pesquisa, bem como a ampliação de contato com outras áreas de servidores penitenciários, tais como Departamento de Tratamento Penal (DTP)³ e Seção de Atendimento ao Servidor da SUSEPE (SASS)4.

Realizamos visitas a tais segmentos com a finalidade de conhecer seus processos de trabalho e, por estes, chegamos a outros, tais como o Departamento de Segurança e Execução Penal (DESEP $\left.{ }^{5}\right)$. A finalidade de tais visitas foi apresentar e discutir os projetos propostos pela Universidade, assim como a coleta de informações a respeito do funcionamento dos respectivos setores e dos processos de saúde-trabalho-formação dos servidores da instituição. Procedemos, ainda, a visitação a alguns Estabelecimentos Prisionais, dentre elas o IPF-POA e a Penitenciária Feminina Madre Pelletier (PFMP), estabelecimentos que eram, ao final do primeiro ano de trabalho, considerados viáveis para o desenvolvimento de pesquisa-intervenção em clínicas do trabalho.

Chegando ao final do primeiro ano das ações, foram tomadas as seguintes decisões: prosseguiríamos investindo na CAP-
-Transversal em seus encontros mensais por ser ela espaço de reunião de servidores pertencentes a instâncias transversais às Casas Prisionais e proporíamos outra CAP no IPF-POA, Casa Prisional essa que vem possibilitando a realização da pesquisa-intervenção em clínicas do trabalho.

\section{Linha II - Coleta de informações}

As informações de maior relevância quando dos primeiros contatos com os setores acima descritos referem-se, especialmente a: dados relativos à saúde, sofrimento e adoecimento de trabalhadores do sistema penitenciário, modalidades de atendimento e assistência e possíveis modos de inserção no âmbito das Políticas Públicas de Saúde, em especial, de Saúde do Trabalhador. Obtivemos tais dados a partir do Relatório de Trabalho da Seção de Atendimento ao Servidor da SUSEPE o qual traz um detalhamento do trabalho deste setor, explicitando seus objetivos e ações realizadas, assim como as dificuldades enfrentadas para dar seguimento às suas atividades e alguns dados quantitativos relativos aos atendimentos. Encontra-se dentre os objetivos específicos do SASS a procura de recursos disponíveis e ações integradas junto à rede científica e a busca do aprimoramento, através da pesquisa, do conhecimento da realidade na qual se trabalha e, com isso, a busca 
da criação de novas perspectivas de intervenções. Os dados do relatório mostram que os atendimentos foram realizados, predominantemente, junto a agentes penitenciários de segurança cujos motivos prevalentes para estes atendimentos foram relativos a problemas no trabalho e familiares.

Também foram colhidos dados relativos à formação para o trabalho na SUSEPE, particularmente em relação às modalidades de curso, tanto de ingresso, quanto de aperfeiçoamento e outros, sua frequência e concepção pedagógica. A esse respeito observa-se a predominância de cursos de formação realizados a partir das necessidades levantadas pelos gestores em uma perspectiva de Educação Continuada ${ }^{6}$. No que tange ao DTP, interessou-nos a concepção de tratamento penal praticada, uma vez que por ela, põem-se em cena dimensões relativas ao trabalho da equipe técnica no Sistema Penitenciário. Pelas visitas às Casas Prisionais nos aproximamos do trabalho de agentes penitenciários administrativos, além do trabalho de agentes de segurança e técnicos. Em relação às Casas Prisionais, levantamos aspectos relativos à organização e funcionamento do trabalho, tais como: quais e quantos são os funcionários que trabalham nas Casas, suas rotinas e atividades, a organização dos regimes de trabalho (carga horária, plantões e diárias) e distribuição do espaço físico.
Tais informações foram colhidas em visitas realizadas junto aos órgãos descritos, oportunidades nas quais conversamos sobre a dinâmica dos setores e obtivemos materiais impressos para leitura e análise, tais como: Matriz Curricular Nacional para a Educação em Serviços Penitenciários? Guia de Referência para a Gestão da Educação em Serviços Penaiss, Relatório de Trabalho da Seção de Atendimento ao Servidor da SUSEPE (SASS, 2010), compilação de textos e leis relativos ao sistema penitenciário e Plano Nacional de Saúde do Sistema Penitenciário. A partir da leitura da Matriz Curricular Nacional destacamos alguns dos aspectos nela previstos como estando em estreita sintonia com os propósitos de nossos projetos: a aposta na formação permanente, a organização de conhecimentos da prática, a parceria entre universidades e escolas penitenciárias, a realização de pesquisas por parte dos alunos/servidores e a afirmação da intersetorialidade. No Guia de Referência para a Gestão da Educação em Serviços Penais, também encontramos aspectos alinhados com nossos propósitos, tais como o estímulo para o investimento em pesquisa-ação e, portanto, se fazendo pela participação ativa dos servidores do Sistema Penitenciário e o fomento para a criação de Núcleos de Pesquisa e Produção Científica, investindo na produção de um saber científico sobre os 
ambientes de trabalho e dinâmicas sócio-prisionais.

As Linhas I, II e III ocorreram em concomitância, evidenciando qualquer impossibilidade de ordenamento no tempo cronológico das ações. Em nosso entendimento, a pretensão inicial de coletar informações imediatamente se converteu em produção de material, tendo em vista que, no processo, novos interrogantes foram sendo produzidos, abrindo veredas para a experiência que nos interessava: a de criar um plano de composição no qual materiais para análise fossem emergindo no momento mesmo em que se instalassem linhas problemáticas a respeito da tríade trabalho penitenciário-saúde-formação.

Interessava-nos não um levantamento exaustivo de informações e materiais que nos permitissem uma descrição objetiva e ampla do que se passa nos setores e áreas visitadas e sim, uma descrição processual, especialmente daquilo que "faz problema" nesta descrição. Assim, pelas visitas a equipe de pesquisadores acadêmicos registrou uma série de informações que nos permitiram conhecer a dimensão organizativa de tais setores e áreas, bem como as questões levantadas pelos trabalhadores desses departamentos e serviços. Este material foi posteriormente sistematizado em forma de novas questões, as quais foram compartilhadas nas reuniões da CAP-Transversal.

Rev. Polis e Psique, 2013; 3(2):185-206

\section{Linha III - Seminários de formação mútua e de análise de situações de trabalho}

Por entre as visitas e reuniões realizadas junto aos setores que se encontravam, inicialmente, em nossos planos (DTP, SASS e ESP), mobilizamos os diversos profissionais a eles vinculados, para a composição da CAP-Transversal, por onde ocorreram os seminários e as situações de análise. Essa CAP, no decorrer do processo, foi sendo sustentada pela ESP, pelo SASS e por Membros do IPF-POA e sua frequência de encontros no primeiro ano das ações foi mensal, sendo a dinâmica das reuniões permanentemente analisada pelo coletivo, gerando novas combinações.

Nesses encontros disparamos a discussão a partir de questões formuladas através das informações registradas nas visitas e procedemos à discussão de alguns textos de referência, de modo a afinarmos a discussão em torno das dimensões epistemológica, conceitual e metodológica dos projetos. Nosso objetivo foi compartilhar as questões formuladas a partir das visitas e investir em um coletivo de análise partilhando conceitos e produzindo ferramentas de trabalho e, ainda, traçar os próximos passos da ação. As proposições iniciais serviram como disparadoras, sendo que as discussões não se ativeram ao proposto, em uma flagrante alusão de que entre o Trabalho 
Prescrito e o Trabalho Real há sempre uma distância. Durante os encontros, os estudantes de Psicologia, Bolsistas do Projeto, registravam os debates para posterior envio dos relatos aos presentes na reunião.

Das questões que trouxemos a partir dos fragmentos das visitas, nos detivemos em três delas: a) O planejamento da formação decorre de um consistente trabalho de análise coletiva de necessidades? b) É possível pensar em atrelar acompanhamento funcional, planejamento da formação e ações em saúde do trabalhador? c) A análise do trabalho em situação pode vir a constituir uma modalidade de formação com caráter permanente?

\section{Linha IV - Planejamento coletivo de projetos de pesquisa-intervenção}

Pelos encontros da CAP-Transversal delineamos os passos para um próximo movimento do projeto - a constituição de outras CAPs para a realização de pesquisa-intervenção em Clínicas do Trabalho, dentro de casas prisionais. A partir das discussões realizadas elegemos o recorte das Casas Prisionais Femininas e fomentamos a constituição de uma CAP no IPF-POA.

\section{Linha V - Elaboração e difusão de material produzido pela experiência}

Ao final do primeiro ano de desenvolvimento do projeto a equipe extensionisRev. Polis e Psique, 2013; 3(2):185-206 ta e de pesquisa elaborou relatório parcial das atividades que foram realizadas, apontando os desafios a serem enfrentados no próximo ano. Tal documento foi lançado à discussão para uma avaliação pelos demais membros da CAP-Transversal que o submeteram à validação. Considerou-se satisfatório o fato de termos explorado possibilidades de atenção à saúde dos trabalhadores do Sistema Penitenciário em indissociabilidade dos processos de formação para e no trabalho, bem como de termos oportunizado a formação mútua de trabalhadores do Sistema Penitenciário e de extensionistas universitários na temática Trabalho Penitenciário-Saúde-Formação. Também entendemos que conseguimos criar condições de possibilidade para a realização de pesquisa-intervenção em Clínicas do Trabalho junto aos servidores da SUSEPE e, ainda, que havíamos dado os primeiros passos na direção de criar instância articuladora na própria SUSEPE, no caso pela CAP-Transversal, para difusão de ações em Clínicas do Trabalho e sustentação de seus efeitos geradores de transformação no que tange à organização e às condições de trabalho. Com relação aos outros dois objetivos, a saber: contribuir para a inserção de profissionais do sistema penitenciário na rede de atenção a Saúde do Trabalhador e favorecer a intersetorialidade produzindo elementos que potencializam Políticas de Saúde do Trabalhador e Políti- 
cas de Justiça e Segurança, entendeu-se que ainda há o que avançar.

Já ao final do segundo ano de realização dos encontros da CAP-Transversal, quando, então, já nos encontrávamos em pesquisa, mantendo tal CAP como dispositivo da mesma, em realização de reunião para avaliação, constatou-se que conseguimos atingir coletivos de análise da atividade no IPF-POA e que a CAP-Transversal incluindo, inicialmente, ESP, SASS e IPF-POA e mais adiante, também, o Departamento de Recursos Humanos (DRH) e o Departamento de Planejamento (DEPLAN), havia conseguido manter seus encontros mensais chegando, inclusive, a abrir duas novas frentes de trabalho, desdobramentos da extensão e da pesquisa realizadas, a saber: investimento pela ESP de uma linha de formação em Saúde e Segurança do Trabalhador Penitenciário e elaboração de uma política institucional de saúde e segurança do trabalhador penitenciário, essa a ser mobilizada, inicialmente, pelo DRH e pelo DEPLAN.

Em relação a primeira frente, pensou-se em propor a continuidade de ações de formação continuada pela ESP enfatizando as discussões no âmbito da Saúde do Trabalhador e a experimentação de uma modalidade de Educação Permanente no serviço penitenciário oportunizada pelos coletivos de análise da atividade de trabalho propostos pela pesquisa, sendo, inclusive os trabalhadores envolvidos nesses coletivos, certificados pela ESP como participantes de atividade de formação. Deste modo entendemos contribuir para a legitimação desses espaços que são, ao mesmo tempo, estratégias de atenção à saúde dos trabalhadores, bem como de formação gerando conhecimento a respeito do trabalho penitenciário por metodologia de co-análise e co-produção com a Universidade.

O presente relato foi elaborado, também, com a finalidade de permitir difusão do material produzido na experiência, expressando nosso empenho em produzir conhecimento coletivamente: pesquisadores-trabalhadores universitários e pesquisadores trabalhadores penitenciários. Proporcionamos, ainda, o encontro de trabalhadores da SUSEPE envolvidos nos projetos em disciplina da Graduação em Psicologia/UFRGS visando a difusão da experiência junto aos alunos. Além disso, tal experiência vem sendo apresentada em eventos científicos 9 e outros.

\section{Por onde andamos na e pela experiência}

Os caminhos percorridos durante implementação das primeiras CAPs foram instigantes e desafiadores. Nos primeiros encontros percebia-se curiosidade e estranhamento por parte dos servidores penitenciários, tendo em vista a dinâmica ora apre- 
sentada, a qual possibilitava um olhar para si mesmos enquanto trabalhadores penitenciários pertencentes a uma instituição tão complexa e contraditória.

Tal estranheza deve-se ao fato de não serem correntes os espaços de escuta, de fala, de análise da instituição penitenciária na direção de enfocar os processos de criação dos trabalhadores em situação de trabalho. Em que pesem as constantes situações em que os trabalhadores penitenciários falam entre si de seu trabalho, tendem a prevalecer queixas relativas às precariedades do sistema não chegando, em muitos casos, a desembocar na análise da atividade de trabalho, o que poderia potencializar as vias para transformação de sua realidade.

Importante fazer este destaque visto que, historicamente, a queixa tem marcado o discurso desses trabalhadores o que reforça uma postura de espera de soluções para seus problemas, acompanhada, ao mesmo tempo, de descrédito quanto a projetos que são propostos retroalimentando um circuito discursivo de que é impossível mudar ou de que nada mais pode ser feito para melhorar sua situação penosa.

A CAP permite relações marcadas pelo encontro, pelo confronto e pelo diálogo crítico entre os saberes das disciplinas acadêmicas e os saberes oriundos da experiência das práticas de trabalho o que nos leva a perceber que o conhecimento dos Rev. Polis e Psique, 2013;3(2):185-206 trabalhadores não é fruto de nenhum talento individual especial, senão que da própria experiência de trabalho partilhada entre os trabalhadores, robustecida pela formação técnica.

Destaca-se que na experiência das CAPs tem sido possível aos trabalhadores dialogarem consigo e com os outros. O que isso significa? Quando Yves Clot (2010b) refere-se à Clínica da Atividade, baseia-se nas constatações de Henri Wallon acerca da observação afirmando que o conhecimento não é um privilégio do observador (pesquisador) mas que a observação gera um trabalho interno no observado que o desacomoda. A questão, então, é a seguinte: o que fazemos com este diálogo interior produzido pelo observado?

$\mathrm{Na}$ esfera da CAP-Transversal queríamos, inicialmente, saber como ela se efetivaria, se os servidores participariam, se as diretorias apoiariam, se os encontros não se esvaziariam. Já na CAP do IPF-POA, fomos nos engajando como atores do processo sem possuir nas mãos réguas ou relógios que permitissem medir nosso destino. A variabilidade de horários que é, inclusive, uma especificidade do trabalho da SUSEPE, não inviabilizou os encontros que seguem acontecendo conforme o campo permite. A CAP tem sido acionada por temas atinentes ao dia-a-dia de trabalho no Sistema Penitenciário ou por imagens em vídeo produzidas pelas 
próprias trabalhadoras, por falas ou acontecimentos que chamem a atenção dos trabalhadores em seu dia-a-dia de trabalho. O objetivo é, coletivamente, avançar dos longos relatos sobre as más condições de trabalho à análise dos processos de trabalho e do trabalho em situação. Neste movimento, vamos percebendo a presença deste diálogo interior e com o outro, ao qual nos referíamos anteriormente, onde percebemos o poder de criação ou a importância de criar no trabalho para que se amplifiquem as possibilidades de saúde do trabalhador penitenciário.

A experiência da análise do trabalho penitenciário nas CAPs não tem sido tarefa fácil por se tratar de uma atividade realizada em um espaço marcado pelo sofrimento, pela vida intramuros, pelo caráter fechado do sistema, com regras, papéis e vocabulário próprios. Muitos são os desafios desta prática diária pois o servidor acaba sendo absorvido pelo ambiente hostil e perverso da prisão o qual o impede, muitas vezes, de crer na possibilidade da mudança. Constata-se que a prisão configura um campo social específico no qual quem dá o tom para cada casa prisional é quem nela habita, o que gera variações no grau de comprometimento dos servidores com a proposta dialógica das CAPs.

Esta dificuldade de realizar um trabalho coletivo no âmbito do trabalho penitenciário pode bem ser identificada na dinâmica da CAP-Transversal, quando os participantes que nela permanecem, frequentemente, passam por um processo de retomada devido à entrada de novos participantes e pela saída de outros, muitas vezes, em decorrência das mudanças de gestores nas casas prisionais envolvidas ou pela adesão tardia de representantes de outros setores.

Além disso, salienta-se que os movimentos da SUSEPE na direção da promoção e da atenção à saúde do servidor penitenciário ainda são incipientes. Deste modo, a CAP vem ao encontro de uma demanda dos servidores contribuindo de forma positiva para o enfrentamento das vulnerabilidades às quais estão submetidos no dia-a-dia de trabalho e que atingem, diretamente, sua saúde. Neste sentido, destaca-se ainda, o fato de que a discussão acerca da segurança no trabalho prisional também vem ganhando espaço, tema esse pouco discutido no espaço da prisão por tratar-se de assunto que suscita controvérsias especialmente em suas relações com a saúde no âmbito das peculiaridades do trabalho penitenciário.

Destacamos que a estratégia da CAP vem oportunizando a experimentação de uma modalidade de promoção de saúde e de formação no trabalho penitenciário localizada nos espaços cotidianos dos trabalhadores marcando um diferencial em relação às estratégias de saúde realizadas em gabinetes profissionais especializados ou, ainda, de 
modalidades de formação situadas exclusivamente em sala de aula.

Vê-se cada vez com maior clareza que o trabalhador é aquele que é capaz de melhor entender os efeitos que a organização e as condições do trabalho provocam, sendo necessário atentar à dinâmica que perpassa a esfera institucional. Em diferentes momentos, os trabalhadores se perguntaram "como a equipe enfrenta e reage à instituição carcerária?”, “quais são as estratégias adotadas"? e, não raras vezes, se responderam que as estratégias adotadas repetem a dinâmica da instituição carcerária. Assim, a CAP vem potencializando um interessante diálogo interior e com os outros, através da análise de sua prática com os pares.

Sabe-se que o desgaste, o sofrimento, o adoecimento e a saúde dos trabalhadores estão diretamente associados aos modos de organização do trabalho, especialmente sob influência de variáveis ligadas à gestão. Sendo assim, compreende-se que os gestores, neste momento do texto considerados os Diretores, Chefias e demais trabalhadores, uma vez que na perspectiva da atividade de trabalho cada trabalhador é gestor de seu trabalho, são considerados "gatilhos" potencialmente concretos para efetivação de mudanças na área da promoção da saúde dos trabalhadores.

Como já mencionamos anteriormente, a CAP-Transversal integra trabalhadores Rev. Polis e Psique, 2013; 3(2):185-206 de diferentes segmentos do Sistema Prisional, sendo que no decorrer dos encontros, a proposta de CAPs se ampliou pela abertura de uma nova frente junto aos servidores que exercem suas funções na ponta, ou seja, junto àqueles que atuam diretamente com pessoas em cumprimento de pena nas casas prisionais. Através de relatos de participantes da CAP-Transversal, constata-se que a conexão entre trabalhadores dos órgãos centrais (ESP, DRH, SASS) e aqueles que estão nos coletivos de análise no IPF-POA vêm contribuindo para a ativação da potência do trabalho e do fortalecimento dos coletivos numa perspectiva de atenção à saúde mediante um processo de análise das relações trabalho-subjetividade-saúde.

Aos poucos, foi-se percebendo que os encontros são fundamentais para que se criem elos entre as intervenções realizadas nas casas prisionais e os órgãos centrais, já que a ideia é a de que a experiência de pesquisa-intervenção que estamos realizando na casa prisional encontre ressonância em outras instâncias organizacionais, considerando-se que a efetividade da proposta clínica do trabalho que empregamos, pressupõe transformação da organização do trabalho. Além disto, a CAP-Transversal, por reunir trabalhadores dos órgãos centrais, oferece nestes encontros, oportunidades para que os mesmos repensem seu próprio trabalho, o que já tem produzido frutos no sentido em 
que se constituíram dois Comitês de Trabalho: um para fomentar a abertura de uma linha de formação na temática da Saúde do Trabalhador Penitenciário e outro para dedicar-se ao delineamento de uma Política Institucional de Saúde do Trabalhador voltada para o trabalhador penitenciário visando sustentar, articuladamente, as ações que já se desenvolvem hoje pela SUSEPE, bem como demais estratégias de promoção de saúde dos trabalhadores que possam ser criadas, especialmente em sintonia com as Políticas Públicas de Saúde e de Saúde do Trabalhador.

\section{Notas}

1 Este projeto foi proposto por professora vinculada ao Instituto de Psicologia/ Departamento de Psicologia Social e Institucional da Universidade Federal do Rio Grande do Sul, e contou com financiamento da Fundação de Amparo a Pesquisa do Estado do Rio Grande do Sul (FAPERGS).

2 A Escola do Serviço Penitenciário do Rio Grande do Sul foi criada pela Lei N 5.570, de 24 de dezembro de 1968 com a atribuição de promover a formação, o desenvolvimento e o treinamento de recursos humanos, em todos os níveis da ação penitenciária.

3 Ao Departamento de Tratamento Penal cabe planejar, coordenar, orientar e supervisionar políticas e ações de saúde física e mental, assistência psicossocial e jurídica, educação, capacitação profissional, cultura, esporte e lazer das pessoas privadas de liberdade, bem como outros julgados convenientes e necessários. (https://www. susepe.gov.rs)

4 A Seção de Atendimento ao Servidor da SUSEPE, esta ligada a Divisão de Recursos Humanos da SUSEPE, foi criada em 2003 e tem como objetivo buscar a melhoria da qualidade de vida dos servidores penitenciários, através de ações preventivas e terapêuticas, que visem oferecer atendimento aos servidores principalmente nas questões relacionadas ao estresse ocupacional e a relação/ intermediação das questões institucionais. Conta com uma equipe de psicólogas que prestam atendimento na capital e em algumas regiões penitenciárias.

5 Ao Departamento de Segurança e Execução Penal, cabe planejar, coordenar, orientar e supervisionar políticas e ações de inteligência e de controle legal, de segurança, operações, escoltas e custódias, bem como o funcionamento dos estabelecimentos penais. (https://www.susepe.gov.rs)

6 A Educação Continuada caracteriza-se por representar uma continuidade do modelo escolar ou acadêmico, centralizado na atualização de conhecimentos, geralmente com enfoque disciplinar, em ambiente didático e baseado em técnicas. São cursos 
periódicos sem sequência constante. Já na Educação Permanente, tal como definida no âmbito da Política Pública de Saúde, propõese incorporar o ensino e o aprendizado à vida cotidiana das organizações e às práticas sociais e laborais, no contexto real em que ocorrem.

7 A Matriz Curricular Nacional pretende ser um documento referencial, que descreve o elenco das principais competências, habilidades, saberes e atitudes que devem ser desenvolvidos junto a todos os que desempenham suas funções no sistema penitenciário. A definição de matriz supõe um conceito mais amplo que o de currículo, buscando oferecer diretrizes gerais para a elaboração dos servidores penitenciários, que possibilitem uma base e filosofia de trabalho comum para cada escola e, ao mesmo tempo, ofereçam uma flexibilidade tal que permita a adaptação dos conteúdos às realidades e demandas próprias de cada estado ou região (Bravo e Azevedo, 2006).

8 O Guia de Referência para a Gestão da Educação em Serviços Penais foi criado com o objetivo de delinear posturas, estruturas e estratégias que favoreçam a consolidação de uma filosofia de enfrentamento e redução das vulnerabilidades que permeiam o Sistema Penitenciário.

9 Referimo-nos à Semana do Servidor: Valorização do Servidor no Espaço Institucional, promovida pela Escola de Rev. Polis e Psique, 2013;3(2):185-206
Serviço Penitenciário e ao XVI Encontro Nacional da Associação Brasileira de Psicologia Social, ambos realizados no ano de 2011.

\section{Referências}

Amador, F., S. (2009). Entre Prisões da Imagem, Imagens da Prisão. Um dispositivo tecno-poético para uma clínica do trabalho. Tese de Doutorado. Universidade Federal do Rio Grande do Sul, Porto Alegre, RS, Brasil.

Brasil. Ministério da Saúde. Secretaria de Gestão do Trabalho e da Educação na Saúde. Departamento de Gestão da Educação em Saúde. (2009) Política Nacional de Educação Permanente em Saúde. Brasília: Ministério da Saúde. Recuperado de http://bvsms. saude.gov.br

Bravo, O. \& Azevedo, R. (2006). Matriz curricular nacional para a educação em serviços penitenciários. Ministério da Justiça. Departamento Penitenciário Nacional.

Canguilhem, G. (2011). Meio e normas do homem no trabalho. Proposições, $12,(2-3), 35-36$.

Carvalhaes, F., F. \& Lima, E., C., S, (2010). Abrir e fechar cadeado: Análise das representações sociais de agentes 
penitenciários sobre o cotidiano de trabalho. Recuperado de http:// www.ppi.uem.br/camposocial/ eventos/i_jornada/051.pdf

CLOT, Y. (2010a). Trabalho e Poder de Agir. Belo Horizonte: Sobrefactum. . (2010b). A Psicologia do Trabalho na França e a Perspectiva da Clínica da Atividade. Fractal: Revista de Psicologia, 22 (1), 207234.

Deleuze, G. (1990). ¿Que és um dispositivo? In: Michel Foucault, filósofo. Barcelona: Gedisa. . (2003). Deux regimes de fous: textes et entretiens (1975-1995). Édition de David Lapoujade. Paris Minuit.

Fernandes, R. C. P., Neto, A., M., S., Sena, G., M., Leal, A., S., Carneiro, C., A., P. \& Costa, F., P., M. (2002). Trabalho e cárcere: um estudo com agentes penitenciários da Região Metropolitana de Salvador, Brasil. Caderno de Saúde Pública, 18(3), 807-816. Recuperado de http://www. scielo.br/scielo.

Harkot-de-La-Taille, E. (2008). O discurso citado na construção do efeito de sentido de identidade em agentes de segurança penitenciária. Discurso \& Sociedade, vol. 2 (3), 475-502. Recuperado de http://www.dissoc.org
Lei $n .8 .080$ de 19 de setembro de 1990 (1990). Dispõe sobre as condições para a promoção, proteção e recuperação da saúde, a organização e o funcionamento dos serviços correspondentes e dá outras providências. Brasília, DF. Recuperado de http://portal.saude.gov. br/portal/arquivos/pdf/lei8080.pdf.

Lopes, R.(2002, Agosto). Psicologia jurídica o cotidiano da violência: o trabalho do agente de segurança penitenciária nas instituições prisionais. Psicologia para América Latina, 0. Recuperado de http://pepsic.bvsalud.org/ scielo.php?script $=$ sci $\operatorname{arttext\& pid=s1870-}$ 350x2002000100004\&ing $=p t \& n r m=$ iso.

Política Nacional de Segurança e Saúde do Trabalhador (2004). Brasília/DF. Recuperado de http://www.mpas. gov.br.

Schwartz, Y.(2000). A Comunidade Científica Ampliada e o Regime de Produção de Saberes. Trabalho \& Educação, Belo Horizonte, 7, 38 - 47. . (2004). Trabalho e Gestão: níveis, critérios, instâncias. In: Figueiredo, M., Athayde, M., Brito, J., \& Alvarez, D. (Org.). Labirintos do Trabalho: interrogações e olhares sobre o trabalho vivo. Rio de Janeiro: DP\&A. 
Souza, P. (2012). Agenciar. In: Fonseca, T., M., G., Nascimento, M., L., \& Maraschin, C. Pesquisar na Diferença: um abecedário. Porto Alegre: Sulina.

Taets, A., R., F. (2011, Julho). Entre o presídio, família e a rua: o dia a dia de mulheres que trabalham como agentes prisionais. IX Reunião de Antropologia do Mercosul. Curitiba, PR, Brasil. Recuperado de http://www. sistemasmart.com.br

Teiger, C. (1998). El trabajo, esse oscuro objeto de la ergonomia. In: Ergonomia: conceptos y métodos. (pp 141-162). Madri: Editoria Computense.

Fernanda Spanier Amador: Psicóloga, Especialista em Saúde Mental Coletiva, Mestre em Psicologia Social e da Personalidade e Doutora em Informática na Educação pesquisando na linha Interfaces Digitais em Educação, Arte, Linguagem e Cognição com Pós-doutorado em Educação (UFRGS). Professora do Departamento de Psicologia Social e Institucional do Instituto de Psicologia da Universidade Federal do Rio Grande do Sul e do Programa de Pós-Graduação em Psicologia Social e Institucional-UFRGS

E-mail: feamador@uol.com.br

Dafni de Melo: Psicóloga, Residente do Programa de Residência Integrada em Saú- de, ênfase de Saúde Mental, do Grupo Hospitalar Conceição

E-mail: dafni.melo@gmail.com

Lucas Bueno: Acadêmico do curso de Psicologia/UFRGS, Bolsista do Programa de Bolsas de Iniciação Científica Voluntário/ UFRGS, Bolsista do Programa de Educação Tutorial do Curso de Psicologia

E-mail: lucasbueno21@yahoo.com.br

Sandra Correia: Técnico Superior Penitenciário - Psicóloga, atuando no Instituto Penal Feminino de Porto Alegre (SUSEPE). Especialista em Segurança Pública e Cidadania/UFRGS

E-mail: $\underline{\text { sandra-correia@,susepe.rs.gov.br }}$

Simone Reginato: Agente Penitenciário Psicóloga, atuando na Secretaria da Segurança Pública - Programa Estadual de Segurança Pública com Cidadania/RS na PAZ, como coordenadora de projetos. Especialista em psicologia clínica e transtornos da adição/Instituto Cyro Martins

E-mail: simone-reginato@ssp.rs.gov.br

Christyanne Alves: Técnico Superior Penitenciário - Assistente Social, atuando na Escola do Serviço Penitenciário. Especialista em Violência Doméstica contra Crianças e Adolescentes/USP. Especialista em Direitos da Criança e do Adolescente/ESMP. Especialista em Direitos Humanos, Cidadania e Processos de Gestão de Segurança/EST

E-mail: christyanne-alves@susepe.rs.gov.br

Recebido em: 11/09/2013 - Aceito em: 16/12/2013 